\title{
The effect of education on adult mortality and disability: a global perspective
}

\author{
Samir KC and Harold Lentzner*
}

\begin{abstract}
Contemporary research primarily in the West offers a strong case for the relationship between formal education and adult health; more education, measured either by level completed or years of schooling, is associated, often in a stepwise fashion, with lower levels of mortality, morbidity and disability. In this study, we attempt to provide a global assessment of that relationship as it pertains to adult disability, using sample data from 70 countries that participated in the World Health Survey. In each of five regions and some of the largest countries outside the West we find that an increase in formal education is associated with lower levels of disability in both younger and older adults. Using the regional education-based differentials and several estimates of growth in education levels, we project levels of disability to 2050 to estimate the health and human capital benefits obtained from investments in education. We find that considering education in the population projection consistently shows lower prevalence of disability in the future, and that scenarios with better education attainment lead to lower prevalence. It is apparent that the educational dividend identified in our projection scenario should be an important policy goal, which, if anything, should be more speedily advanced in those countries and regions that have the greatest need.
\end{abstract}

\section{Introduction}

Two related issues rank high on the list of problems facing the world in the new century, both of which revolve around the existence of deprivation and disparity. The first is the burden of poverty and ill health in the developing world, particularly in Africa and parts of Asia and Latin America, which account for most of the 'bottom billion.' Although much effort has been expended over the

\footnotetext{
* Samir KC (correspondence author) World Population Program, International Institute for Applied Systems Analysis (IIASA), Schlossplatz 1, 2361 Laxenburg, Austria. Email: kc@iiasa.ac.at

Harold Lentzner, World Population Program, International Institute for Applied Systems Analysis (IIASA), Laxenburg, Austria.
} 
past half century and billions of dollars spent, the lives of the citizens of these countries are all too often still characterised by hunger, illness, childhood mortality and despair. Many of the countries in these regions are still unable to sustain the political stability and economic growth and generate the human capital needed to emerge from dependence on support from the developed world. Moreover, within these countries there is a wide gulf between the lives of the bulk of the population and a small affluent elite.

In the more developed world, nations face social and economic challenges related to changing demographics; ageing populations are often characterised by older workers, increasing social support and growing health care costs due largely to chronic illness and disability. Here as well, inequity exists, since individuals at the lower end of the social ladder are more likely to fall ill, lose or leave their jobs due to ill health or disability, and require costly health care and income support.

To address these issues, countries across the globe have initiated a variety of programmes designed to enhance health and general well-being and reduce disparities. In these efforts, expanding education and improving the quality of education are often explicit goals, and to most people this seems eminently reasonable because there seems to be a connection between education and well-being even if the details of the relationship are not clear. In Europe and North America much is known about the relationship between formal education and health. At the macro level, countries with higher levels of education usually have longer life expectancies and better health profiles, and within countries, the more educated have better health, lower disability and longer life expectancy. Much less is known about education-based health differentials in other parts of the world although the literature available from Latin America, Asia and Africa suggests that there is a similar relationship.

In most multidisciplinary endeavours, scientists attack a question using a variety of theoretical models, applications and vocabulary and, when survey data are required, use different data collection strategies, concepts, questionnaire designs and analytical approaches. Diversity has its merits; the strength of a relationship is often confirmed in this manner. Such has been the case in our efforts to understand the education/health relationship but now, in addition, comparability of survey instruments and measurements is needed as well, to assess similarities and differences across the globe. Fortunately, a number of harmonised cross-national efforts have been undertaken, including the World Health Survey. ${ }^{1}$ Results from these studies will shed more light on the similarities and differences of the education/health relationship and offer clues as to the direction of adult health over the next half century.

Other cross-national efforts using comparable questions include the Demographic and Health Surveys (DHS), the Survey of Health, Ageing and Retirement in Europe (SHARE), the US Health and Retirement Survey, the English Longitudinal Study of Ageing and a number of national health interview surveys. 
In this study we begin with a literature review that examines the relationship between education and adult mortality and morbidity, its shape and pattern, as well as its potential causal mechanisms, or pathways. We then offer a global summary of current, education-based, adult disability patterns using data from the World Health Survey (WHS). Finally we use the education/disability relationships obtained from our analysis to show the impact of increased educational attainment on the growth of human capital over a 50 -year period.

\section{Background}

\subsection{Education and adult health}

\subsubsection{The mortality gradient}

In the modern era, interest in the relationship between formal education and adult health as a measure of socio-economic status (SES) may arguably be said to have been raised by Aron Antonovsky (1967) and then measured by Kitagawa and Hauser (1973). To compute death rates by level of education, Kitagawa and Hauser matched a sample of death certificates with 1960 US census data files; their results not only showed that men and women with higher education have lower mortality rates and live longer than those with lower education, but also that there was a significant, consistent gradient across as many as seven ordered categories of completed schooling. Similar gradients were evident for occupation and income but Kitagawa and Hauser argued for the primacy of education, pointing out that it is a) constant over the lifespan of an individual, b) applies with equal validity to men and women, workers and the retired, and c) is not subject to a reverse causal path, like income. Significant education-based gradients were also found in other early analyses using US mortality data (Rogot et al. 1992; Elo and Preston 1996).

In Europe, researchers first used cross-national compilations of countryspecific linked data from the 1970s and 1980s; inequality indices by years or levels of education showed that while substantial differences across countries existed, the pattern of decreasing mortality with increasing education was pervasive (Valkonen 1989; Kunst and Mackenbach 1994). Not only did this early body of work document the disparity in death rates between the best and worst educated adults in most Western nations, but a number of trend analyses using different sources and different approaches showed that the disparity in educationbased mortality was widening (Feldman et al. 1989; Pappas et al. 1993; Mackenbach et al. 2003).

In recent years a variety of analyses in the West have continued to document the existence of an education gradient: some, like Mackenbach (Mackenbach et al. 1999; Mackenbach et al. 2003), charting trends in death rates across countries 
(Avendano et al. 2004; Fawcett et al. 2005), others charting them within a single country (Kinsey et al. 2008; Rau et al. 2008), for a single point in time in several countries (Huisman et al. 2005; Ezendam et al. 2008), for trends in life expectancy (Crimmins and Saito 2001; Huisman et al. 2005; Deboosere et al. 2009; Ezendam et al. 2008) or for older adults (Feinstein 1993; Bassuk et al. 2002; Lièvre et al. 2008).

The availability of death records and census data in eastern and central European countries provided researchers with the data needed to examine the link between education and mortality. In general, the inverse relationship between education and mortality among adults is strong and, with the possible exception of the Czech Republic, the negative relationship has increased over time, when measured either by rate ratios or life expectancy (Mackenbach et al. 1999; Leinsalu et al. 2003; Kalediene and Petrauskiene 2000; Shkolnikov et al. 2006; Dennis et al. 1993; Shkolnikov et al. 1998; Plavinski et al. 2003).

A limited number of studies have considered the education/mortality relationship in countries outside of Europe and North America. Emergent countries in Asia are of interest in part because they have often experienced dramatic advances in both education and health. In the Republic of Korea, researchers using unlinked census and death records examined the impact of education on all and selected-cause mortality, computing mortality rates and relative indices for both men and women aged 35-64 in 1995, and found a gradient across five levels of education similar to that found in western European countries (Khang et al. 2004, and see also Son et al. 2002). A prospective cohort study in Japan among adults aged 40-59 in four geographical areas (Ito et al. 2008) underlined again the familiar negative relationship between broad categories of educational attainment and mortality. However, a review of cancer mortality and survival rates in several south-east Asian countries (Kurkure and Yeole 2006) identified a positive relationship between education and breast cancer among women in Greater Mumbai.

In China, Liang and associates used data from a three-year mortality follow-up (1991-94) of a sample of older adults aged 60+ in the city of Wuhan. The results indicate that education measured by number of years of schooling has a direct negative effect on the risk of dying (Liang et al. 2000). A more recent study analysed data from the Chinese Longitudinal Healthy Longevity Survey on men and women 80 years of age and older and found that even at that age educated women in urban areas had lower mortality than non-educated women, particularly those in rural areas (Zhu and Xie 2007).

Published research on differential mortality is rare in the developing world where levels of education are low but the impact of only a few years of formal education may well be high. Two studies from Bangladesh, one of the poorest nations in the region, offer evidence of the impact of a basic education on adult mortality (Mostafa and van Ginneken 2000; Hurt et al. 2004). In a multivariate analysis of determinants of mortality among adults aged 60 and older between 
1974 and 1996, Mostafa and van Ginneken found that for both men and women, those who were literate had significantly lower mortality. Hurt and colleagues looked at women of 45 and older and their husbands and concluded that those with some education, whether Qur'anic or secular, had significantly lower mortality; the husbands had even lower mortality if their wives also had some education. Finally, among a rural population aged 20 and over in Vietnam, higher education was associated with lower mortality (Huong et al. 2006).

\subsubsection{Morbidity differentials}

Measurements of morbidity cover several dimensions, most frequently: 1) a general health assessment, obtained by asking respondents or their proxies how they rate their health; 2) the prevalence or incidence of disease, usually obtained by asking interviewees whether they have a particular illness or a set of diseases or conditions; ${ }^{2} 3$ ) the prevalence or incidence of physical or cognitive difficulties or limitations; 4) a composite indicator of healthy life. Researchers have often gone beyond identifying the nature of the relationship to understanding why and developing theories. In this section we summarise work on the nature of the relationship by region and in the next section we turn to investigations of causality.

\section{Europe and North America}

In Europe, cross-national studies examining the relationship between education and adult health have confirmed the negative association identified for mortality (Cavelaars et al. 1998; Sihvonen et al. 1998; Dalstra et al. 2005). Cavelaars compared differentials in 11 western European countries using prevalence measures from separate national health surveys. As a consequence, there were a variety of comparability issues, but nonetheless, results showed a negative relationship across three levels of education (less than upper secondary, upper secondary and university) and poorer health, measured by perceived general health, long term prevalence of disabilities or health problems and chronic conditions. Dalstra computed the odds ratios of disease prevalence among individuals aged 25-79 for two broad educational groups, using non-standardised national health surveys from eight western European countries. There was a much higher prevalence of stroke, diabetes and nervous system disorders among the lower educated group and a less dramatic but still significant differential for heart disease in all countries combined. However, cancer showed no education-based disparity.

Other morbidity analyses registered point-in-time education differentials for coronary heart disease in Finland (Kivimaki et al. 2007), many forms of cancer in

2 Disease prevalence is sometimes obtained from actual diagnostic tests or from disease registries, for example cancer registries, and these measurements are considered the 'gold standard'. 
Italy (La Vecchia et al. 1992), multi-morbidity in Germany (Nagel et al. 2008), disability in Spain (Graciani et al. 2004) and general health status among older adults aged 65-84 in ten western European countries (Rueda et al. 2008)

Members of a collaborative project, known as Micmac, estimated levels of disability and disability transition rates for 12 European countries using longitudinal panel data from the European Community Household Panel (ECHP) (Majer et al. 2008). Disability was defined as having a chronic physical or mental problem that hampered daily activities. Age-specific disability incidence, recovery and mortality rates were calculated for three levels of education (lower secondary and below, higher secondary and tertiary) from approximately 670,000 observations for persons 16 years of age and older. Those with the highest education had a lower rate of onset of disability and a higher rate of recovery than those in the two lower education groups. Irrespective of whether individuals were disabled or free of disability, death rates did not differ by level of education.

In the US, Kraus used a composite index of education and occupation and found an inverse relationship between SES and cardiovascular disease (Kraus et al. 1980) while Pincus showed that the frequencies of chronic diseases reported by adults aged 18-64 decreased with increasing education (Pincus et al. 1987). More recently, Qureshi et al. analyzed data from a follow-up to the National Health and Nutrition Examination Study, to show that individuals with less than high school education, particularly those aged 50 and younger, were at greater risk for several cardiovascular conditions than those with more education (Qureshi et al. 2003). Some early economic studies also identified positive effects from education primarily among men reporting on their general health (Grossman 1975; Rosen and Taubman 1982; Leigh 1983; Lairson et al. 1984; Desai 1987; Kemna 1987).

Educational disparities have also been noted in estimates of healthy life often for older adults. Longitudinal data from a population of older whites and blacks in the US were used to estimate total and active life expectancy (Guralnik et al. 1993). In this prospective study, education proved to be a more important predictor of active life expectancy than race; those with higher education had from 2.4 to about 4 additional years of active life, depending on the sex/race subgroup (see also Crimmins et al. 1996; Molla et al. 2004). In a later study, Crimmins and colleagues looked at trends in healthy life, defined in this study as being free from limitation in normal activity, and found a widening disability gap among non-institutionalised adults at age 30 , between those with the lowest (0-8) and the highest education (13+) (Crimmins and Saito 2001). A number of other researchers have explored the relationship between SES and health using micro data from several large longitudinal studies of older Americans (see for example Cai and Lubitz 2007; Clark et al. 2007; Freedman et al. 2008). 


\begin{abstract}
Asia
Explorations into education-based health gradients in Asia have, until recently, been quite rare. In China, $\mathrm{Wu}$ and colleagues found relatively consistent negative gradients across four categories of education in the level of chronic illness in the rural areas of six provinces in 1993 and 2001, particularly among women (Wu et al. 2004). Data from two rounds of the China Health and Nutrition Surveys (1997 and 2000) show an inverse relationship between education and the onset of functional decline among a sample of older men and women aged 55 and older (Beydoun and Popkin 2005). Finally, an analysis employing data from the 2005 Inter-Census Survey suggests adults with more education report higher levels of good health and that for both men and women and in both rural and urban areas, the disparity between the least educated and the rest of the population increases with age (Lowry and Xie 2009).
\end{abstract}

\begin{abstract}
Africa
In Africa, studies of the risk of acquiring HIV show that the relationship between education and health can be very dynamic. Analyses using data collected over three decades present an evolving picture; a relatively early study in rural Uganda (Smith et al. 1999) employing data on HIV seroprevalence in 1990 for the population aged 13 and older clearly indicated that those with primary or secondary schooling were at higher risk than those with no schooling, even after controlling for a number of socio-demographic and behavioural factors. Fortson, analysing relatively recent Demographic and Health Survey (DHS) data from 5 African countries, also finds that for most of these countries people with 6 years of schooling were more likely to be infected with the HIV virus than those with no education, but those with 12 years or more had lower rates (Fortson 2008). A number of other studies in several different countries have also identified higher risk levels for those with more education (Grosskurth et al. 1995; Fylkesnes et al. 1997; Quigley et al. 1997; Kilian et al. 1999). In contrast, Glynn found no evidence of an increased risk for those with more schooling, but modest evidence of a protective effect (Glynn et al. 2004). Neither Gregson (Gregson et al. 2001) nor Hargreaves (Hargreaves and Glynn 2002) found any association between education and HIV prevalence. Michelo charts an interesting transition in Zambia using data from three population-based surveys of both rural and urban areas taken in 1995, 1999 and 2003 (Michelo et al. 2006). Over this period, those with higher education relative to those with less went from having higher to lower odds of having HIV. This transition has also been noted in a number of other localities (Kelly et al. 1999; Fylkesnes et al. 2001; Crampin et al. 2003).
\end{abstract}




\subsubsection{Causal models}

More education is related to lower adult mortality, morbidity and disability. But how does education work? What are the links? Efforts to find the relevant links have focused on several sets of intermediate factors: those related to material resources such as food, medical care and working conditions, those related to behavioural risk factors such as tobacco use, alcohol consumption, sedentary life style and obesity and those related to personal and social conditions (Haan et al. 1989). ${ }^{3}$

\section{Behavioural risk factors}

Because chronic diseases in large part determine levels of mortality and morbidity, researchers have developed an interest in identifying their associated risk factors and their relationship to formal education. Smoking, alcohol abuse, a sedentary lifestyle and lower nutritional intake have been found to be associated with lower levels of education (Chen et al. 2006; Gilman et al. 2008; Saavedra et al. 2008). A number of risk factor studies attempt to measure the contribution of a single risk factor to overall education-based health disparities. Often the approach assesses the degree to which the disparity in mortality or morbidity between those at the educational extremes declines when the risk factor of interest is added to the model. For example, for adults aged 45-74 in New Zealand in the late 1990s, the all-cause mortality rate ratio, lowest to highest educational level, adjusted for age and ethnicity, was reduced by 21 per cent for men and 11 per cent for women after adjustment for current and former smoking (Blakely and Wilson 2005). This and other studies with a public health perspective (for example, Bemelmans et al. 2006) frequently include scenarios which project declines in mortality or morbidity based on reductions in individual modifiable risk factors, thus providing an alternative to more dramatic and costly structural changes.

As a group, behavioural risk factors have been found to explain a significant portion of the educational differential, particularly for cardiovascular disease. Using mortality follow-up data on 50-year-old men in Uppsala, Sweden, Kilander and colleagues found that controlling for smoking, physical activity and dietary biomarkers effectively wiped out the educational gradient for cardiovascular disease mortality and reduced excess mortality from cancer among the lowest category by about half (Kilander et al. 2001; see also Laaksonen et al. 2008). However, other studies have shown that important educational differentials remain after controlling for modifiable lifestyle factors (Lantz et al. 2001 and also Pitsavos et al. 2002; Nagel et al. 2008). The adherents of a 'fundamental cause'

3 Roughly 15 years after Haan, Cutler and Lleras-Muney (2006) produced a set of candidate mechanisms which fit fairly easily into the Haan categories. Several may be antecedent to risk factors - value of the future, information and cognitive skills, and preferences or risk aversion - and explain why in part educational differentials exist for the most important behavioural risk factors 
approach (Link and Phelan 1995; Link and Phelan 2000; Phelan and Link 2005) are sceptical of focusing on these standard behavioural risk factors, not because they are unimportant in understanding chronic disease processes but because they are simply the latest - and perhaps not the last - that reflect an enduring and persistent SES gradient. Link and Phelan argue that:

"...the reason for such persistent associations, and the essential feature of fundamental social causes, is that they involve access to resources that can be used to avoid risks or minimize the consequences of disease as it occurs. We define resources broadly to include money, knowledge, power, prestige and interpersonal resources such as social support and social networks..."

The persistence of the gradient is the key to this perspective as it has endured over changes in the disease regime and the nature of the mechanisms. Many of the factors mentioned - material resources, knowledge, power and social networkshave also been identified in education-based models, along with lifestyle factors as mediators, so in some sense this notion has become embedded in the causal structures. However, in Link and Phelan's model, the three traditional measures of SES "do not adequately assess the full range of social resources that are important to health; they include a more general notion of social class, power, prestige and social capital as distal to prevailing risk mechanisms."

\section{Psychosocial factors}

Psychosocial factors, such as depression, social isolation, stress, loss of control have also been the subject of focused study for some time (Gallo and Matthews 2003). As an example, Ruberman and colleagues found that the negative educational gradient in survival following a heart attack (Myocardial Infarction, MI) was erased when variables related to life stress and social isolation were included in a regression model (Ruberman et al. 1984). However, an analysis of mortality outcomes found that depression and hopelessness accounted for little of the social class variation once a number of other factors were taken into consideration (Fiscella and Franks 1997). In another study using data from the US and Finland, Cohen and colleagues found that controlling for a set of psychosocial variables reduced, in a stepwise fashion, the odds ratio of poor health for those in three lower educational groupings (Cohen et al. 1999).

\section{Multi-factor models}

Since material, lifestyle and psychosocial factors have all been shown to mediate the effect of SES, it stands to reason that researchers have assembled models with variables from two or more of these components (Stronks et al. 1996; Schrijvers et al. 1998; Van Oort et al. 2005). Schrijvers and associates used six years of mortality follow-up data from the Netherlands to generate the relative risk of mortality across four categories of education; the model applied had the significant material factors-financial problems, employment status and an income proxy - affecting mortality both directly and indirectly through a set of 
behavioural risk factors-alcohol use, smoking, Body Mass Index (BMI) and physical activity - which also had direct effects. Adding both sets of factors to the model reduced the relative educational hazards by more than $75 \%$ for each of the three lower educational groups. Van Oort and colleagues included a set of psychosocial factors, which were in part mediated through material circumstances and risk factors. With a few more years of mortality follow-up and employing the same four categories of education, their analysis showed 1) elimination of any significant differential when all explanatory factors were in the model and 2) the most important components were material factors (in this case, type of health insurance as a proxy for income, financial problems and housing tenure), acting directly on mortality and indirectly through both psychosocial and behavioural risk factors.

Another mortality study of adults in South Korea identified nine 'pathway' or mediator variables, including household income, type of health insurance and driving status for material factors, feelings of sadness and depression, level of stress and marital status for psychosocial factors, and smoking, alcohol consumption and exercise for health behaviour (Khang et al. 2009). The unmediated model showed a strong negative gradient across three categories of education. The inclusion of all three sets of factors reduced the overall relative risk by about 40 per cent. Material factors appeared to be the most important in reducing the relative educational inequality ( 29 per cent), followed by behavioural and psychosocial factors (16 and 7 per cent, respectively).

\subsection{Projecting the health of adult populations}

If, as we suppose, the transformative power of education is universal, policy makers and international aid organisations need to understand the impact more education will have on population health and the growth of human capital. One way to do this is to develop and employ models and population-based projections that incorporate these education/health relationships; alternative projections may well provide powerful examples of the impact that increases in education have on health and human capacity. This is the topic of the next two sections.

Population projections take what we know about the past and the present, specifically the current demographic composition and trends in fertility, mortality and migration, make informed assumptions about the future and project the outcome in terms of age and sex structure of the population. Many policy and research questions need population to be disaggregated by other observable and measurable characteristics of the population, such as rural/urban place of residence, educational attainment, labour force participation, parity, household and health status (Lutz and KC 2010). 


\section{Analysis of the World Health Survey}

In this section we address gaps in geographical coverage by describing the relationship between comparable measures of education and disability across more than one third of the countries of the world.

\subsection{Data and methods}

Data for this analysis come from the WHS, a collection of sample surveys of the adult population of 18 years of age and older in 70 countries across the globe (Table 1). Data were collected in 2002/2003 with personal interviews conducted in the local language using standardised survey instruments. Respondents provided information on demographic characteristics, health status, risk factors, access and utilisation of health services and health care expenditure. Countries had the option of using several different sample strategies, each of which

Table 1:

WHS countries used in the analysis by region

\begin{tabular}{|c|c|c|c|c|}
\hline Africa & Asia & Western Europe & Eastern Europe & Latin America \\
\hline Burkina Faso & Bangladesh & Austria & Georgia & Brazil \\
\hline Chad & China & Belgium & $\begin{array}{l}\text { Bosnia and } \\
\text { Herzegovina }\end{array}$ & Dominican Rep. \\
\hline Comoros & India & Denmark & Croatia & Ecuador \\
\hline Congo & Israel & Finland & Czech Republic & Guatemala \\
\hline Ivory Coast & Kazakhstan & France & Estonia & Mexico \\
\hline Ethiopia & Laos & Germany & Hungary & Paraguay \\
\hline Ghana & Malaysia & Greece & Latvia & Uruguay \\
\hline Kenya & Myanmar & Ireland & Russia & \\
\hline Malawi & Nepal & Italy & Slovakia & \\
\hline Mali & Pakistan & Luxembourg & Slovenia & \\
\hline Mauritania & Philippines & Netherlands & Ukraine & \\
\hline Mauritius & Sri Lanka & Norway & & \\
\hline Morocco & Turkey & Portugal & & \\
\hline Namibia & UAE & Spain & & \\
\hline Senegal & Vietnam & Sweden & & \\
\hline South Africa & & United Kingdom & & \\
\hline Swaziland & & Australia & & \\
\hline \multicolumn{5}{|l|}{ Tunisia } \\
\hline \multicolumn{5}{|l|}{ Zambia } \\
\hline Zimbabwe & & & & \\
\hline
\end{tabular}


produced samples representative of the total population. The survey was initiated to respond to the challenges facing health policy makers who required reliable baseline information to evaluate programmes and improve the health of their populations (WHO 2000).

\section{Variables used in the analysis are defined as follows:}

Activities of Daily Living ADL disability - We used two questions in the "Health Status' module of the WHS to create our dichotomous dependent variable. Respondents were asked, "Overall in the last 30 days how much difficulty did you have with moving around?" and in a second question using the same time frame, "... how much difficulty did you have with self-care, such as washing or dressing yourself?" (Figure 1) Respondents who answered that they had 'severe' or 'extreme' difficulty or could not do these activities in either question were defined as having ADL disability; those who said they had 'none' or only 'mild' or 'moderate' difficulty were classified as not ADL disabled. ${ }^{4}$

Figure 1:

Creation of the ADL disability variable

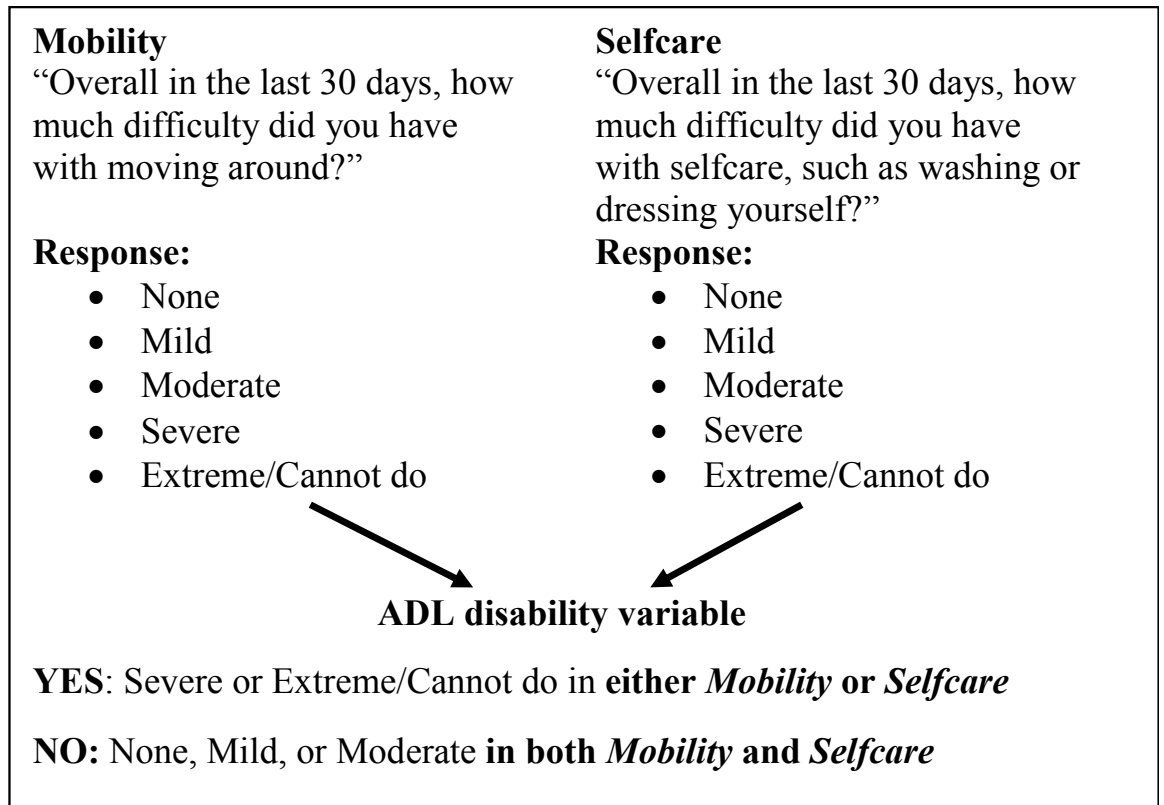

Self-rated health (SRH) disability - For an alternative measurement of disability, we used a question on general health where respondents were asked to rate their health on the day of the interview as either 'Very good', 'Good',

$4 \quad$ We considered including 'moderate difficulty' in our disability category but opted for using only those with severe or extreme difficulty because of the clarity of those responses. 
'Moderate', 'Bad' or 'Very Bad'. In line with the definition of ADL disability, where we used the two most restricted categories, individuals responding 'Bad' or 'Very Bad' were categorised as having SRH disability. Because different time periods and characterisations of health were used, it was expected that some individuals who were classified as being ADL disabled might not be SRH disabled and vice versa. We will show how these two sets of disability are associated. At the same time we created a third definition of disability, where a person is categorised as disabled if he or she is either ADL disabled or SRH disabled

Educational attainment - The WHS asks respondents for the highest level of education completed and the number of completed years of schooling. We used highest level of schooling and combined the seven categories listed on the questionnaire into four categories; no education, primary, secondary and tertiary education. ${ }^{5}$

Demographic - We ran regression models separately for men and women using five age groups $(30-39,40-49,50-59,60-69$ and 70+). Separate models were run for each of the five regional groupings and for ten major countries; Brazil, China, India, Russia, Pakistan, Philippines, Ethiopia, South Africa, Vietnam and Turkey.

To partially control for country level effects on the level of disability, in a second model we included the Multidimensional Poverty Index (MPI), a summary index incorporating a set of education, health and standard of living indicators (Alkire and Emma-Santos 2010). The index ranges from zero to one, with the lowest score of 0.000 for the most developed countries and the highest for the least developed, for example Niger, with an index of 0.667. Inclusion of the MPI is largely to check for the model's sensitivity to the country's socio-economic condition.

In this analysis we focus on the relationship between level of completed education and ADL disability although we also show results for SRH disability and the composite index. To model the relationship between education and disability we used the logit of the probability of being disabled (which is the log of odds of being disabled) as the dependent variable, with age and education as explanatory variables. Therefore:

Log (odds of being disabled $)=$ Age group (as categorical variable $)+$ Sex + Education (as categorical variable) $+\{$ Country's poverty index-MPI\}

Age (30-89) was introduced as a categorical variable with four dummy variables in the model (age 30-39 as base). Education was also a categorical variable; initially, we ran the model for four levels of education, but collapsed secondary and tertiary into one category, at least secondary, because of small cell sizes, particularly at older ages, in many developing countries. The loss of

5 For Turkey and Mexico we converted years to level of education using official definitions. 
information is minimal as there is no big overall difference in the proportion disabled between these two groups (as seen in Table 2).

The analysis was repeated for three definitions of disability (ADL, SRH and ADL-SRH). Country specific sampling weights were used in the regression, therefore giving greater weights for the samples from countries with larger populations. Available pre-sampling weights corresponding to the overall population distribution in each country were used to construct weights for individual samples corresponding to the overall population distribution in the region.

\subsection{Results}

Table 2 shows the regional distributions of the sample population by age, sex and level of education. The two Europe regions have the oldest populations, about one fifth in the 30-39 age group and a little less than two fifths at 60+, whereas Africa has the youngest adult population with about two fifths in the 30-39 age group and 20 per cent aged $60+$. The educational disparities are striking, with the proportions of those having no formal schooling ranging from 46 per cent in Africa, 27 per cent in Asia and less than 10 percent in the other regions. Each of the regions had more women than men in the sample.

Fourteen per cent of the sample population in eastern Europe was ADL disabled. In the other four regions the proportion disabled ranged from nine per cent in Africa to five per cent in Latin America. Table 3 shows the percentage of ADL disability in each education group in each region for the sample. As for regional differences, eastern Europe appears to have the highest level of disability at older ages followed by Africa and Asia, with Latin America and western Europe showing the lowest levels. Eastern Europe also has the highest levels of disability at all levels of education. Regional and country differences in levels of disability must be viewed with caution due to the subjective nature of the questions and the degree to which cultural and socio-economic factors may systematically impact reporting. 
Table 2:

Age, sex and education structure in the sample

\begin{tabular}{|c|c|c|c|c|c|}
\hline \multicolumn{6}{|c|}{ Sample (proportion) } \\
\hline & \multirow[t]{2}{*}{ Africa } & \multirow[t]{2}{*}{ Asia } & \multirow[t]{2}{*}{ Western Europe } & \multirow{2}{*}{$\begin{array}{c}\text { Latin } \\
\text { America }\end{array}$} & \multirow{2}{*}{$\begin{array}{l}\text { Eastern } \\
\text { Europe }\end{array}$} \\
\hline & & & & & \\
\hline \multicolumn{6}{|l|}{ Age } \\
\hline $30-39$ & $19083(38 \%)$ & $23561(36 \%)$ & $4574(22 \%)$ & $15902(34 \%)$ & $2980(20 \%)$ \\
\hline $40-49$ & $12685(26 \%)$ & $18225(28 \%)$ & $4548(22 \%)$ & $11539(25 \%)$ & $3388(23 \%)$ \\
\hline $50-59$ & $7997(16 \%)$ & $11025(17 \%)$ & $4047(19 \%)$ & $8006(17 \%)$ & $2958(20 \%)$ \\
\hline $60-69$ & $5490(11 \%)$ & $7233(11 \%)$ & $3783(18 \%)$ & $5860(13 \%)$ & $2710(18 \%)$ \\
\hline $70+$ & $4389(9 \%)$ & $4557(7 \%)$ & $4042(19 \%)$ & $4825(10 \%)$ & $2912(19 \%)$ \\
\hline \multicolumn{6}{|l|}{ Sex } \\
\hline Female & $26618(54 \%)$ & $34882(54 \%)$ & $12308(59 \%)$ & $26015(56 \%)$ & $9407(63 \%)$ \\
\hline Male & $23026(46 \%)$ & $29719(46 \%)$ & $8686(41 \%)$ & $20117(44 \%)$ & $5541(37 \%)$ \\
\hline \multicolumn{6}{|l|}{ Education } \\
\hline No Education & $23012(46 \%)$ & $17694(27 \%)$ & $610(3 \%)$ & $3012(7 \%)$ & $191(1 \%)$ \\
\hline Primary & $17541(35 \%)$ & $22989(36 \%)$ & $5371(26 \%)$ & $15765(34 \%)$ & $2095(14 \%)$ \\
\hline Secondary & $6895(14 \%)$ & $17569(27 \%)$ & $10939(52 \%)$ & $25559(55 \%)$ & $8563(57 \%)$ \\
\hline Tertiary & $2196(4 \%)$ & $6349(10 \%)$ & $4074(19 \%)$ & $1796(4 \%)$ & $4099(27 \%)$ \\
\hline Total & $49644(100 \%)$ & $64601(100 \%)$ & $20994(100 \%)$ & $46132(100 \%)$ & $14948(100 \%)$ \\
\hline
\end{tabular}

Table 3:

Empirical proportion of disabled per education level

\begin{tabular}{lccccc}
\hline Education & Africa & Asia & $\begin{array}{c}\text { Western } \\
\text { Europe }\end{array}$ & Latin America & $\begin{array}{c}\text { Eastern } \\
\text { Europe }\end{array}$ \\
\hline No Education & 0.12 & 0.16 & 0.20 & 0.13 & 0.37 \\
Primary & 0.07 & 0.08 & 0.10 & 0.07 & 0.29 \\
Secondary & 0.04 & 0.04 & 0.05 & 0.04 & 0.12 \\
Tertiary & 0.04 & 0.03 & 0.03 & 0.02 & 0.09 \\
\hline Total & 0.09 & 0.08 & 0.06 & 0.05 & 0.14 \\
\hline
\end{tabular}

Table 4 shows the result of our regression of ADL disability on age and education, separately for females and males. All values are significant at the 0.05 level or higher except for those identified by $n s$. The odds of reporting severe or extreme difficulty in mobility or self-care increases by age; for eastern European females the odds increase rapidly with age, almost nine times at age 60-69 compared with women at age 30-39 and almost three times for Asian and Latin American females. For men, as age increases the odds at age 60-69 increase by as much as six times in western and eastern Europe compared with the odds at age 30-39.

For both sexes and in all five regions (except for eastern European males with at least secondary education), the prevalence of disability declined significantly with increasing education. The odds of reporting ADL disability for women with 
no education compared to those with a primary education is the highest (more than double) in Latin America (2.43 times) and lowest in Africa (1.19 times); for women with at least a secondary education, the odds ratio is lowest (less than half) in Asia (0.46) and highest in eastern Europe (0.82).

Table 4:

Regression of ADL on age and education: odds ratio

\begin{tabular}{|c|c|c|c|c|c|c|}
\hline & & Africa & Asia & $\begin{array}{l}\text { Western } \\
\text { Europe }\end{array}$ & $\begin{array}{c}\text { Latin } \\
\text { America }\end{array}$ & $\begin{array}{l}\text { Eastern } \\
\text { Europe }\end{array}$ \\
\hline \multicolumn{7}{|c|}{ Female } \\
\hline & \multicolumn{6}{|l|}{ Age } \\
\hline & $30-39$ & 1.00 & 1.00 & 1.00 & 1.00 & 1.00 \\
\hline & $40-49$ & 1.39 & 1.27 & 1.62 & 1.55 & 2.58 \\
\hline & $50-59$ & 2.08 & 1.82 & 3.39 & 1.91 & 3.82 \\
\hline & $60-69$ & 3.49 & 2.92 & 4.07 & 2.92 & 8.77 \\
\hline & $70+$ & 5.74 & 6.37 & 11.07 & 4.81 & 21.3 \\
\hline & \multicolumn{6}{|l|}{ Education } \\
\hline & No Education & 1.19 & 1.74 & 1.93 & 2.43 & 1.73 \\
\hline & Primary & 1.00 & 1.00 & 1.00 & 1.00 & 1.00 \\
\hline & $\begin{array}{l}\text { At least } \\
\text { secondary }\end{array}$ & 0.62 & 0.46 & 0.53 & 0.52 & 0.82 \\
\hline \multicolumn{7}{|l|}{ Male } \\
\hline & \multicolumn{6}{|l|}{ Age } \\
\hline & $30-39$ & 1.00 & 1.00 & 1.00 & 1.00 & 1.00 \\
\hline & $40-49$ & 1.09 & 1.58 & 1.39 & 0.93 & 2.87 \\
\hline & $50-59$ & $1.8^{\mathrm{ns}}$ & 2.80 & $3.93^{\mathrm{ns}}$ & $1.85^{\mathrm{ns}}$ & 3.89 \\
\hline & $60-69$ & 3.26 & 4.50 & 6.02 & 3.16 & 6.19 \\
\hline & $70+$ & 5.65 & 6.41 & 7.89 & 6.46 & 14.45 \\
\hline & \multicolumn{6}{|l|}{ Education } \\
\hline & No. Education & 1.38 & 1.21 & 2.00 & 2.35 & 2.56 \\
\hline & Primary & 1.00 & 1.00 & 1.00 & 1.00 & 1.00 \\
\hline & $\begin{array}{l}\text { At least } \\
\text { secondary }\end{array}$ & 0.75 & 0.65 & 0.88 & 0.61 & $0.64^{\mathrm{ns}}$ \\
\hline
\end{tabular}

Note: All values are significant at the 0.05 level or higher except for those identified by $n s$

To illustrate further, we estimated from our model the proportion of disabled older adults age 50-59 by level of education separately for men and women in each of five major regions of the world (as shown in Figure 2). The educational gradient is clearly visible in all regions though to a varying degree. 
Figure 2:

Estimated prevalence of ADL disability: distribution for men and women aged 50-59

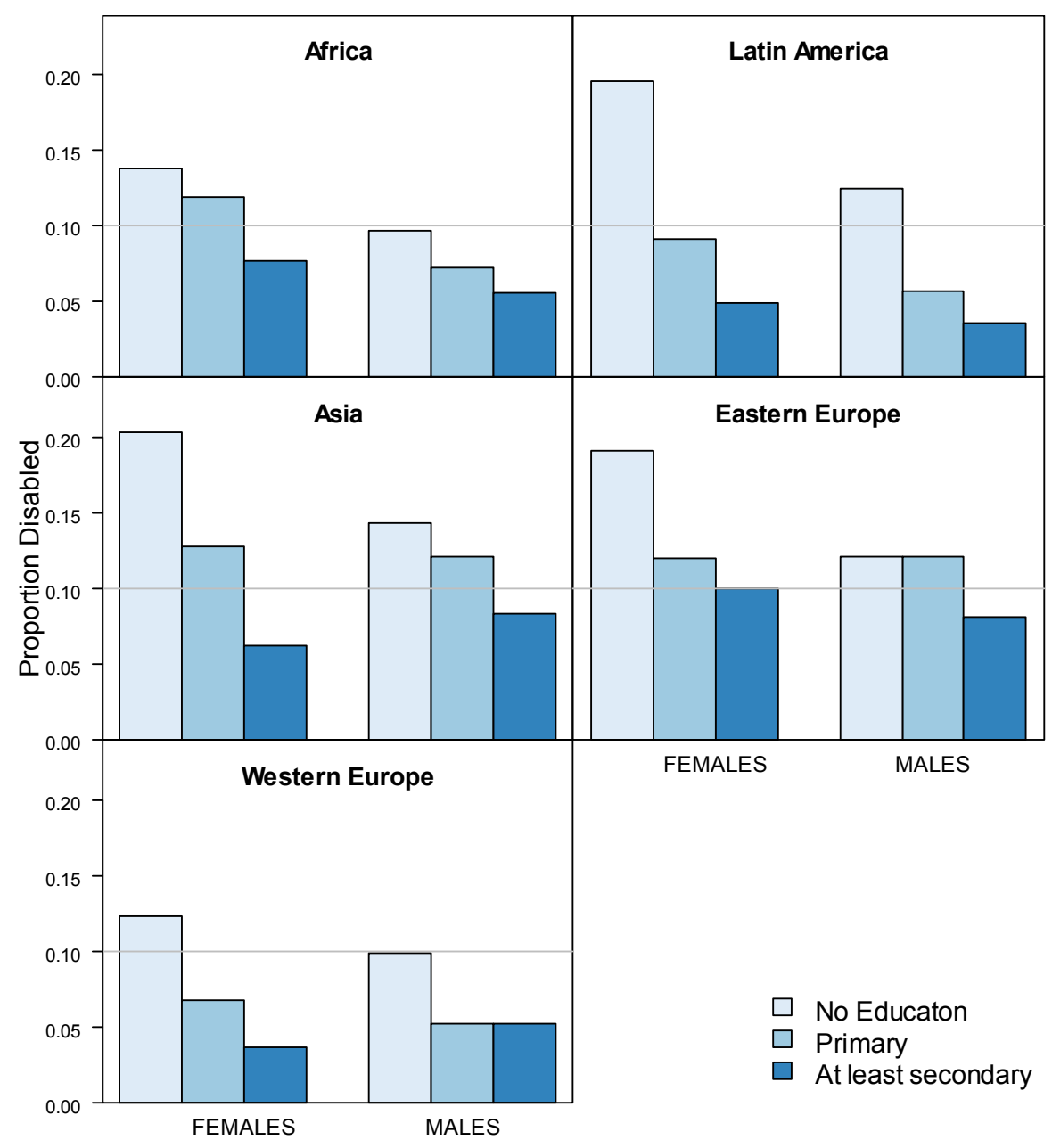


Table 5 shows our analysis extended to include results from ten participating countries representing all regions except western Europe. In general, the pattern of odds ratios above 1 for individuals with no education and below 1 for those with at least a secondary education persists across these countries. Five of the countries-Brazil, Philippines, Russia, South Africa and Turkey-all displayed these relationships for both men and women, although the values were not always statistically significant. In Vietnam a similar pattern was evident, although none of the odds ratios were statistically significant. In addition all or most of the values are insignificant for Pakistan and a few other countries. A major reason for the instability in the results is small cell size. For example, in Pakistan there were only three women aged $60+$ with at least a secondary education and none of them reported ADL disability.

Table 5:

Regression of ADL disability on age and education for 10 selected countries: odds ratio

\begin{tabular}{|c|c|c|c|c|c|c|}
\hline \multicolumn{4}{|c|}{ Females } & \multicolumn{3}{|c|}{ Males } \\
\hline & No education & Primary & $\begin{array}{c}\text { At least } \\
\text { secondary }\end{array}$ & No education & Primary & $\begin{array}{l}\text { At least } \\
\text { secondary }\end{array}$ \\
\hline Brazil & 2.36 & 1.00 & 0.45 & 2.23 & 1.00 & 0.55 \\
\hline China & 3.24 & 1.00 & $2.22^{\mathrm{ns}}$ & 3.97 & 1.00 & $0.61^{\mathrm{ns}}$ \\
\hline Ethiopia & $0.86^{\mathrm{ns}}$ & 1.00 & $0.70^{\mathrm{ns}}$ & 2.18 & 1.00 & $1.19^{\mathrm{ns}}$ \\
\hline India & $0.90^{\mathrm{ns}}$ & 1.00 & 0.50 & $0.91^{\mathrm{ns}}$ & 1.00 & 0.65 \\
\hline Pakistan & $3.42^{\mathrm{ns}}$ & 1.00 & $2.37^{\mathrm{ns}}$ & $0.73^{\mathrm{ns}}$ & 1.00 & 0.36 \\
\hline Philippines & 1.93 & 1.00 & 0.47 & $1.26^{\mathrm{ns}}$ & 1.00 & 0.50 \\
\hline Russia & 3.25 & 1.00 & $0.94^{\mathrm{ns}}$ & $8.96^{\mathrm{ns}}$ & 1.00 & $0.64^{\mathrm{ns}}$ \\
\hline South Africa & $1.16^{\mathrm{ns}}$ & 1.00 & 0.34 & 2.50 & 1.00 & $0.66^{\mathrm{ns}}$ \\
\hline Turkey & 2.13 & 1.00 & 0.40 & 1.61 & 1.00 & 0.38 \\
\hline Vietnam & $1.49^{\mathrm{ns}}$ & 1.00 & $0.34^{\mathrm{ns}}$ & $1.51^{\mathrm{ns}}$ & 1.00 & $0.64^{\mathrm{ns}}$ \\
\hline
\end{tabular}

Note: All values are significant at the 0.05 level or higher except for those identified by $n s$

\section{Sensitivity analysis}

We repeated the model to check the sensitivity of including a country level poverty/development index, MPI. Figure 3 compares the two approaches; Model 1, without MPI, represented by a solid line and Model 2, with MPI represented by dashed line. Only those odds ratios that were statistically significant are shown. In general there was little difference in the values obtained for the two models; however, among African men and women the addition of the MPI increased the odds ratios for those with no schooling but reduced the odds ratios for both men and women in Latin America and for Asian men. 
Figure 3:

Odds ratio of reporting ADL disabled-at $5 \%$ level of significance-for each region (including MPI)

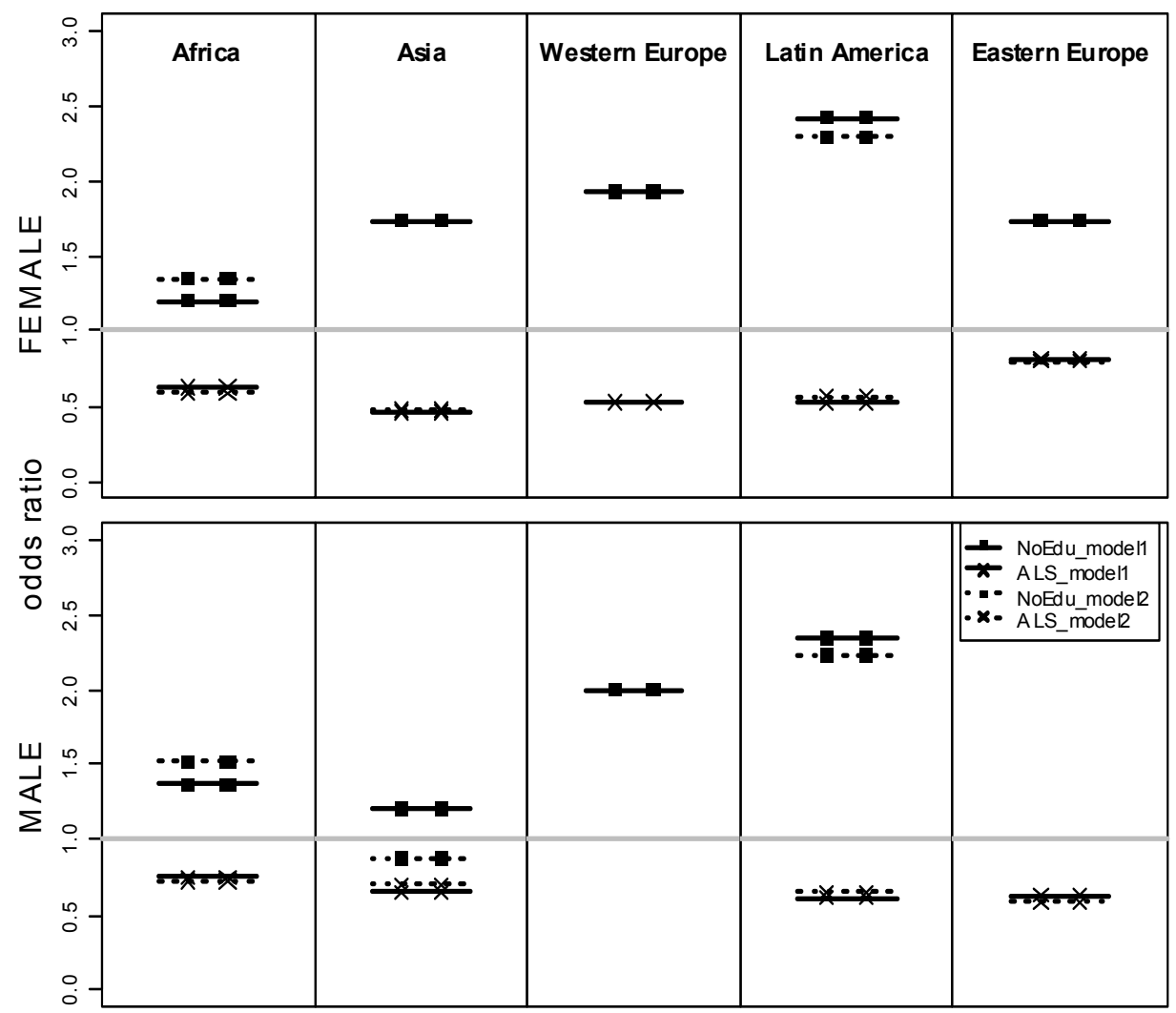

Note: Model $1=$ not including MPI; Model $2=$ including MPI

Table 6 shows similar results when we consider different measurements of ADL disability, namely SRH and our joint ADL-SRH measurement. All results point in the same direction except in a few cases where the odds ratio is statistically insignificant. However, conformity between reporting ADL and SRH disability at the individual level is low as seen by larger values (intercept term) for SRH and ADL-SRH compared with the same for ADL. The baseline value of SRH is consistently higher than the ADL for both sexes in all five regions. ${ }^{6}$

SRH asks about a person's general health on the day of interview whereas ADL is about his/her condition in the previous month before the interview and consists of only physical health dimension. 
Table 6:

Regression of ADL/SRH/ADL-SRH on age and education for each region: odds ratio (compared with those aged 30-39, primary educated)

\begin{tabular}{|c|c|c|c|c|c|c|c|}
\hline \multirow[b]{2}{*}{ Region } & \multirow[b]{2}{*}{$\begin{array}{c}\text { Educational } \\
\text { attainment }\end{array}$} & \multicolumn{3}{|c|}{ Female } & \multicolumn{3}{|c|}{ Male } \\
\hline & & $\mathrm{ADL}$ & SRH & ADL-SRH & $\mathrm{ADL}$ & SRH & $\overline{\text { ADL-SRH }}$ \\
\hline \multirow[t]{3}{*}{ Africa } & Intercept & 0.06 & 0.09 & 0.14 & 0.04 & 0.06 & 0.09 \\
\hline & $\begin{array}{l}\text { No } \\
\text { education }\end{array}$ & 1.19 & 1.31 & 1.21 & 1.38 & 1.45 & 1.45 \\
\hline & $\begin{array}{l}\text { At least } \\
\text { secondary }\end{array}$ & 0.62 & 0.67 & 0.65 & 0.75 & 0.59 & 0.68 \\
\hline \multirow[t]{4}{*}{ Asia } & Intercept & 0.08 & 0.09 & 0.14 & 0.05 & 0.06 & 0.09 \\
\hline & $\begin{array}{l}\text { No } \\
\text { education }\end{array}$ & 1.74 & 1.85 & 1.84 & 1.21 & 1.19 & 1.18 \\
\hline & $\begin{array}{l}\text { At least } \\
\text { secondary }\end{array}$ & 0.46 & 0.50 & 0.49 & 0.65 & 0.55 & 0.60 \\
\hline & Intercept & 0.02 & 0.05 & 0.07 & 0.01 & 0.02 & 0.04 \\
\hline \multirow{3}{*}{$\begin{array}{l}\text { Western } \\
\text { Europe }\end{array}$} & No & 1.93 & 3.35 & 3.45 & 2.00 & 3.86 & 3.34 \\
\hline & $\begin{array}{l}\text { education } \\
\text { At least } \\
\text { secondary }\end{array}$ & 0.53 & 0.48 & 0.46 & $0.88^{\mathrm{ns}}$ & 0.80 & 0.74 \\
\hline & Intercept & 0.05 & 0.08 & 0.12 & 0.03 & 0.05 & 0.08 \\
\hline \multirow{3}{*}{$\begin{array}{l}\text { Latin } \\
\text { America }\end{array}$} & No & 2.43 & 2.57 & 2.57 & 2.35 & 3.01 & 2.77 \\
\hline & $\begin{array}{l}\text { education } \\
\text { At least } \\
\text { secondary }\end{array}$ & 0.52 & 0.53 & 0.53 & 0.61 & 0.52 & 0.56 \\
\hline & Intercept & 0.04 & 0.10 & 0.12 & 0.04 & 0.11 & 0.11 \\
\hline \multirow{2}{*}{$\begin{array}{l}\text { Eastern } \\
\text { Europe }\end{array}$} & No & 1.73 & $1.06^{\mathrm{ns}}$ & $1.16^{\mathrm{ns}}$ & $2.56^{\mathrm{ns}}$ & 3.20 & $1.83^{\mathrm{ns}}$ \\
\hline & $\begin{array}{l}\text { education } \\
\text { At least } \\
\text { secondary }\end{array}$ & 0.82 & 0.81 & 0.81 & 0.64 & 0.68 & 0.70 \\
\hline
\end{tabular}

Note: All values are significant at the 0.05 level or higher except for those identified by $n s$

\section{Projecting the level of adult health}

\subsection{Data and methods}

In this section we look at the potential impact of the growth of formal education on adult health across broad geographical regions. We used IIASA's world population projections by age, sex and education for the period 2000-2050 (KC et al. 2010) and estimated adult disability up to 2050 in two different ways. We first applied a constant age/sex profile of ADL disability without considering our 
observed educational differentials. Then we factored in the education/disability relationships obtained from the WHS analysis along with several different educational attainment scenarios across the same interval. More than 100 countries (covering approximately 90 per cent of the world's population) grouped into five regions were used in this exercise.

The population projections are based on the demographic method of multistate population projection that was developed at IIASA during the 1970s and is now a well-accepted method (Rogers 1975; Lutz 1994; Lutz et al. 1999; Lutz and Goujon 2001). Our procedure for each country can be summarised as follows:

1. A baseline population distribution by five-year age group, sex and level of educational attainment is derived for the year 2000.

2. For each five-year period, cohorts move to the next highest five-year age group.

3. Mortality rates are applied, specific to each age, sex and education group, and to each period.

4. Age and sex-specific educational transition rates are applied.

5. Age, sex and education-specific net migrants are added to or removed from the population.

6. Estimates of ADL disability obtained from our logistic regressions are applied for each age, sex and education group to all countries in each of the four regions for which there is data for making educational projections, in order to derive the overall level of ADL disability.

Crucial to our education/health projection is the assumption of growth in levels of education over time. For this descriptive analysis we used three distinctly different education scenarios: 1) a Constant Enrolment Number (CEN) scenario, 2) the Global Education Trend (GET) scenario and 3) the Fast Track (FT) scenario. Because CEN assumes no change in the size of enrolment across the decades it is the most pessimistic of the three. The GET scenario assumes a convergence towards global trends and as such is somewhat conservative. As an illustration, it takes a typical country about 40 years to raise female participation in primary schooling from 50 per cent to 90 per cent and over 30 years after that to reach 99 per cent. This may seem discouragingly slow but reflects the empirical average. While some countries have expanded access much more quickly, others have stagnated and made even less progress during the final decades of the 20th century and this is reflected in the average slope.

Figure 4a shows India in 2000 and the baseline empirical distribution of its population aged 15 and above, by age, sex and education. The multi-state pyramid shows that there were a large number of Indian women with no formal education and a larger number of men with higher education. The pyramid has a larger base which reflects the increasing population of younger cohorts. Figure $4 \mathrm{~b}$ shows the pyramid for India in 2050 according to the GET scenario. There will still be some Indians with no formal education, but large numbers of the population are 
expected to have completed at least lower secondary education. A declining base is the effect of a lower level of fertility in the future. Figure $4 \mathrm{c}$ shows the population pyramid in 2050 according to the CEN scenario. We see a broader base compared with Figure 4a, which is mainly due to the higher level of fertility associated with the lower level of education of mothers. The numbers of people with a higher level of education (primary and more) are constant with the rest of the population having no formal education. Comparing Figure $4 b$ and $4 c$, the difference is mainly due to the different education profiles of mothers.

\section{Figure 4a-4d:}

Population structure by age, sex and educational attainment: empirical (2000) and projected (2050) for different education scenarios
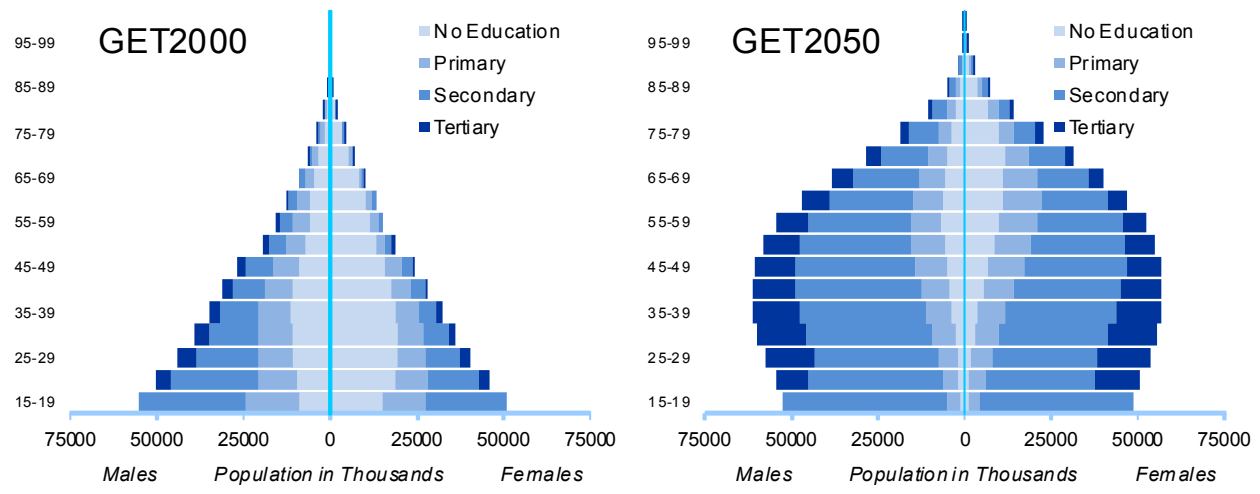

4c India 2050 - Constant Enrollment 4d India 2050 - Fast Track Scenario Number Scneario
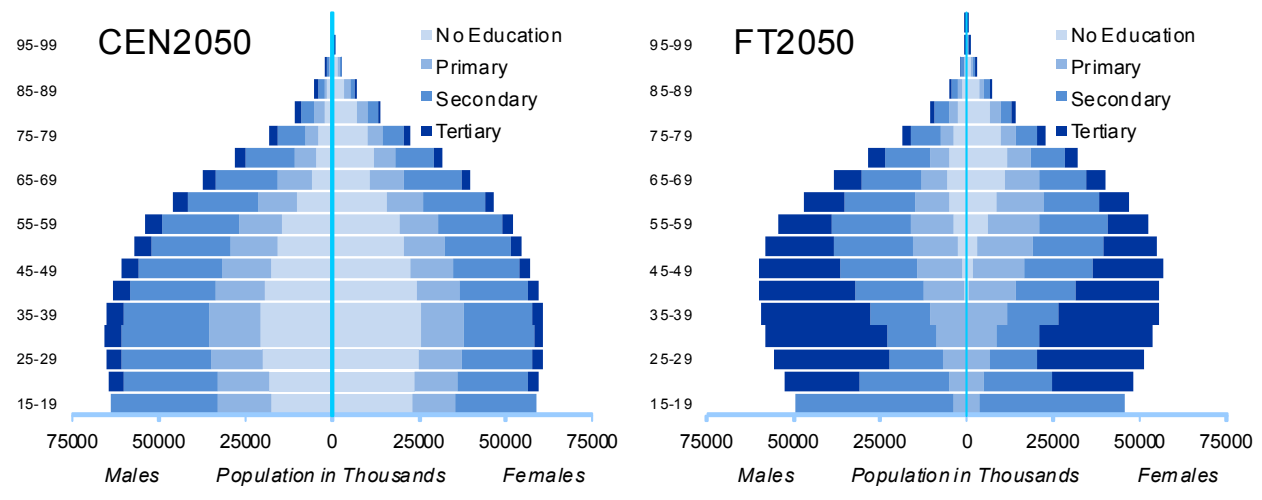

In contrast, the FT scenario is the most optimistic and is based on the GET scenario but with specific education targets to reach by some specific time, with accelerated growth if needed (for details see $\mathrm{KC}$ et al., 2010). The target is $60 \%$ of those 30-34 attaining tertiary education by the year $2050,50 \%$ of those $20-24$ obtaining at least a lower secondary education by the year 2030 and $90 \%$ by 
2050 , and $99 \%$ of those $15-19$ attaining primary education by the year 2025 (corresponding to the 5-9 age group in 2015). Figure 4d shows the population distribution in 2050 according to the FT scenario with an even smaller base than GET in Figure 4b, as well as a larger number of people with higher education.

The results of projecting the level of adult health are shown in $5 \mathrm{a}-5 \mathrm{e}$ for people aged 30-74. Without factoring in education and its 'known' relationship to health, we get very different estimates on the possible level of adult disability. Disability will rise under this scenario (shown by lines marked by - NES: No education scenario). In Asia, disability prevalence for women increases from $12.9 \%$ by about 3.5 percentage points, and for men by 2.3 percentage points from $8.2 \%$, from 2000 to 2050. Latin America and eastern European regions have a similar level of increase, 2.3-2.5 percentage points for women and 1.5-1.7 for men. The western European region, with an old age profile, shows small increases over the 50-year interval; similarly, Africa with the youngest population displays a small increase in prevalence in the second half of the period.

With education taken into account, under all three scenarios there will be reductions in disability, more so for adult women than men. Under the GET scenario the increase in disability is clearly less marked in all regions except eastern Europe and among males in western Europe. As an example, at the end of the series, the prevalence is about 6.5 percentage points lower than the constant scenario for adult Asian women, or 1.8 percentage points lower than the same scenario for Asian men. A similar impact is seen in Latin America. At the end of the series disability under the FT scenario in Africa and Asia is slightly lower than under the GET scenario. By contrast, prevalence is higher with constant enrolment (CEN) particularly for women in African, Asia, and Latin America. 
Figure 5a-5e:

Projected prevalence of ADL disability for age group 30-74 in 5 regions
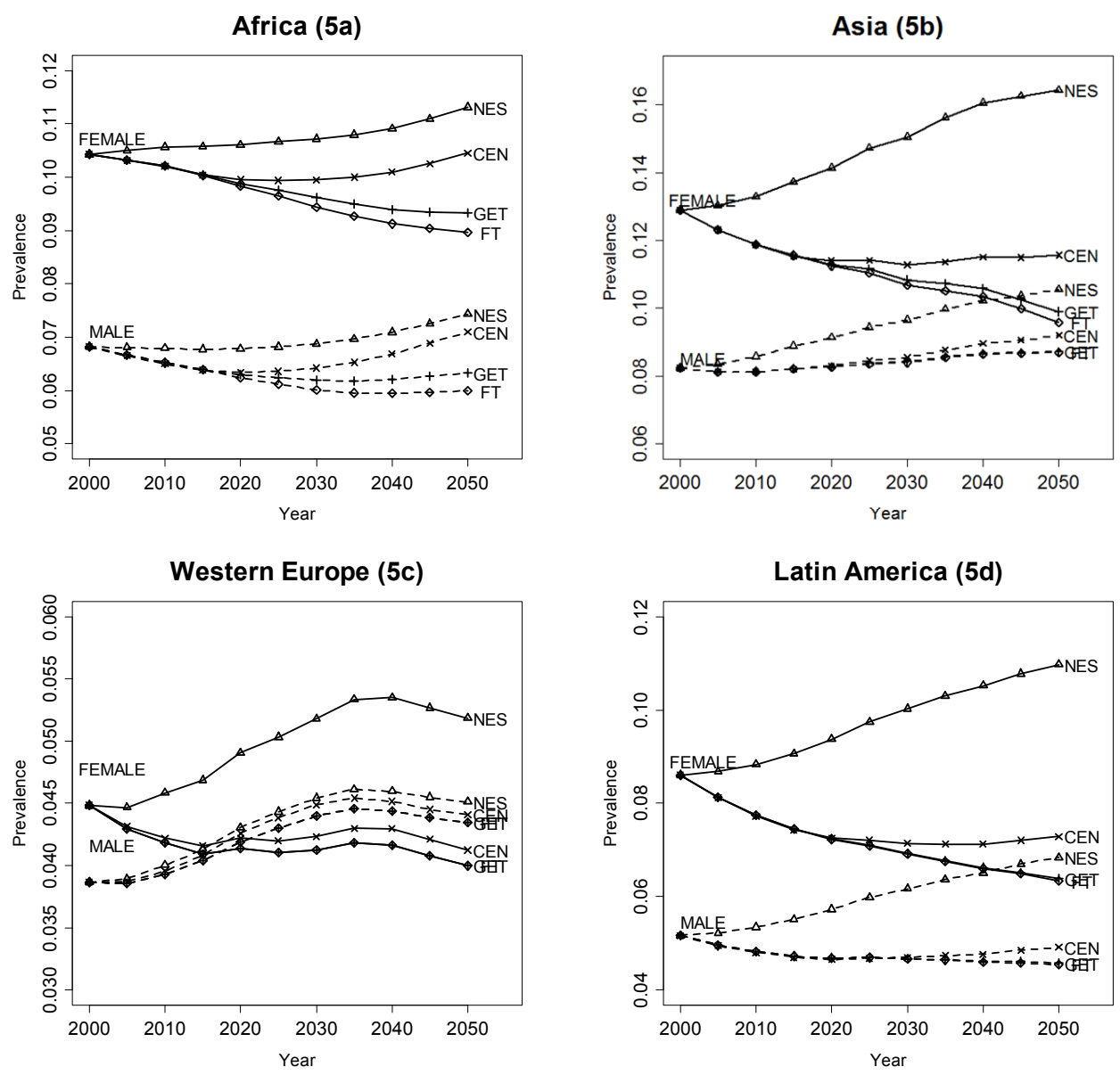

Eastern Europe (5e)

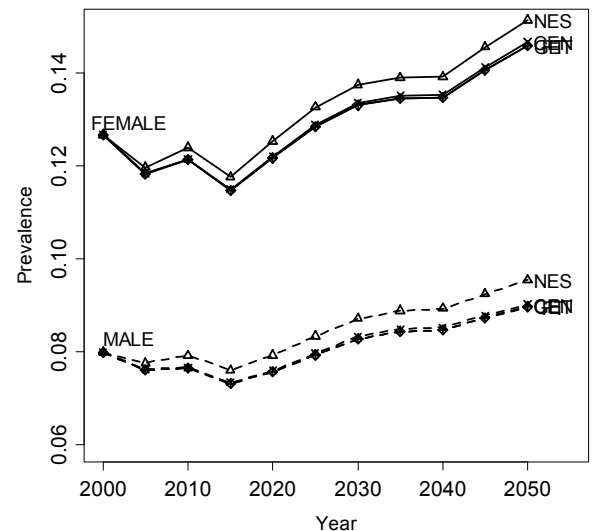

Legend:

NES - No Education Scenario

GET-Global Education Trend scenario

CEN - Constant Enrolment Number scenario

FT-Fast Track scenario

Note:

Prevalence scale varies across the regions 


\section{Discussion}

Research in the Western world has shed a good deal of light on the relationship between education and health and the possible mechanisms at work. With an understanding of the body of the existing research we have attempted to present a global picture of education-based differentials in adult health, using results from 70 countries that conducted the same WHO health survey in 2002-2003.

Results from our regional analysis show clearly that in each of the 4 nonWestern regions, the negative relationship between education and poor health, well-documented in western Europe and North America, is evident, both for ADL and SRH disability. We also find a range in this disparity. As measured by the odds ratio, the disparity between individuals with no education, compared with those with primary education, is strongest in Latin America for both women and men, and weakest in Africa for women and in Asia for men. At the other end, the education differential in ADL disability between those with at least secondary education and those with only primary education is most profound in Asia for women and in Latin America for men, and weakest in eastern Europe for women and western Europe for men.

Our examination of the education/adult health connection in ten of the largest countries in the world, accounting for about half the world's population, illustrated more diversity but in large measure confirmed the regional findings. In Brazil and Turkey, education differentials were statistically significant across the three levels of education for both sexes. For many of the other countries, the negative relationship was apparent if not statistically significant. More research is needed to derive a better understanding of the variation in this relationship and, in particular, those settings where more education does not appear to be related to better health.

Two health measurements drawn from three questions were used in the analysis, one related to chronic physical disability, which we have referred to as ADL disability, and the other to self-appraisal of one's general health. We chose ADL disability as our primary index because of its potential for affecting the growth of human capital. No measurement is without its limitations and with respect to those used in this analysis and other respondent reports of health there is a variety of critical commentary (see for example, National Research Council 2009). It should be noted that assessment of difficulty in undertaking the tasks was solicited, unlike in some surveys, without asking if the respondent received help or used assistive devices such as a cane or walker. Certainly the additional information obtained by asking these extra questions would have been useful for understanding the nature of the limitation better.

Self-assessments are by nature subjective and when differences in reporting are systematic across age groups or sex or cultural groups they may not provide true differences in health states but perspectives or expectations. Anchoring vignettes attempt to control for these differences and a set of these vignettes are 
included in the WHS. Researchers (Salomon et al. 2004; Rice et al. 2010) using data from WHS countries have concluded that employing anchoring vignettes is a good way to adjust for cultural differences in self-rated health; however, others (Vargas-Palacios et al. 2006) for Mexico and (Damacena et al. 2005) for Brazil have shown that anchoring vignettes have less efficacy and are not appropriate for these countries. Since, the use of vignettes is still debated, we decided not to use them in our analysis. Furthermore, our focus was not on cross-cultural comparisons.

Our literature review highlighted studies that concentrated on several sets of intermediate factors through which education may impact health. However, there are other competing explanations. One possibility is that there is another factor which influences both education and adult health. It has been suggested for example, that differences in the way individuals prioritise time determines both educational attainment and future health (Fuchs 1982). Another possible interpretation follows from 'moving the arrow' in the other direction, that is, suggesting that childhood health constrains or determines our educational choices and more generally, our socio-economic status. This has been called a number of things - health-related selection, social drift or social selection - and falls under the general rubric of reverse causation or selectivity. Some recent commentary has gone beyond an either/or argument and suggested a more complex process involving multiple causal streams in which both educational attainment (or social class) and childhood health have a direct and indirect causal link to adult health. If this is the case, rather than dismissing the notion of selectivity it would be far better to attempt to understand the complex pathways that help determine adult health (Goldman 2001; Palloni 2006).

Of course, for this to occur it is necessary to have information on health status during or prior to schooling. While this line of inquiry is beyond the scope of this analysis, it is worth noting that a good deal of research has been undertaken attempting to understand important factors determining the health of adults over their lifetime better. ${ }^{7}$ In the end it is hard to dispute the notion that child health and even intergenerational health has some impact on educational attainment and academic achievement and, as a consequence, complicates the relationship between education and adult health. What we might conclude from analyses that consider early life factors is that while the path to adult health inequality does not begin at the gates of formal education, its differential impact is a critical component in a more complex model.

Investigators have used sample surveys with retrospective information (Freedman et al. 2008; Blackwell et al. 2001; Hayward and Gorman 2004), measured data across the life course (Wadsworth and Kuh 1997; Hertzman et al. 2001; Viner and Cole 2005; Power and Elliott 2006; Gale et al. 2008), and biomarkers (Seeman et al. 2008). Life-course theory and models, as they pertain to adult health and chronic disease in particular, argue for comprehensive consideration of physical and social health risks from gestation to adulthood, and often more distal factors like the health of parents and grandparents (Smith et al. 2001; Ben-Shlomo and Kuh 2002; Elstad 2005; Pollitt et al. 2005). 
To conclude, our projections of adult health, using the multi-state techniques developed at IIASA, have illustrated the importance of including the education/health connection in any comprehensive human capital development planning. It is apparent that the educational dividend identified in our projection scenario should be an important policy goal, which, if anything, should be more speedily advanced in those countries and regions that have the greatest need.

\section{Acknowledgements}

The authors wish to acknowledge the support of the European Commission Grant ERC-2008-AdG 230195 Future Society.

\section{References}

Alkire, S. and M. Emma-Santos. 2010. "Acute multidimensional poverty: a new index for developing countries." OPHI Working Papers 38.

Antonovsky, A. 1967. "Social class, life expectancy and overall mortality." Milbank Memorial Fund Quarterly 45: 42.

Avendano, M., A. E. Kunst, M. Huisman, F. van Lenthe, M. Bopp, C. Borrell, T. Valkonen, E. Regidor, G. Costa, A. Donkin, J. K. Borgan, P. Deboosere, S. Gadeyne, T. Spadea, O. Anderson, and J. P. Mackenbach. 2004. "Educational level and stroke mortality: a comparison of 10 European populations during the 1990s." Stroke 35(2): 432-437.

Bassuk, S. S., L. Berkman, and B. C. Amick. 2002. "Socioeconomic status and mortality among the elderly: findings from four US communities." American Journal of Epidemiology 155(6): 520-533.

Bemelmans, W. H., F. van Lenthe, R. Hoogenveen, A. Kunst, D. J. Deeg, P. A. van den Brandt, R. A. Goldbohm, and W. M. Verschuren. 2006. "Modeling predicted that tobacco control policies targeted at lower educated will reduce the differences in life expectancy." Journal of Clinical Epidemiology 59(9): 1002-1008.

Ben-Shlomo, Y. and D. Kuh. 2002. "A life course approach to chronic disease epidemiology: conceptual models, empirical challenges and interdisciplinary perspectives." International Journal of Epidemiology 31(2): 285-293.

Beydoun, M. A. and B. M. Popkin. 2005. "The impact of socio-economic factors on functional status decline among community-dwelling older adults in China." Social Science and Medicine 60(9): 2045-2057.

Blackwell, D. L., M. D. Hayward, and E. M. Crimmins. 2001. "Does childhood health affect chronic morbidity in later life?" Social Science and Medicine 52(8): 1269-1284.

Blakely, T. and N. Wilson. 2005. "The contribution of smoking to inequalities in mortality by education varies over time and by sex: two national cohort studies, 1981-84 and 1996-99." International Journal of Epidemiology 34(5): 1054-1062.

Cai, L. and J. Lubitz. 2007. "Recent trends in education differentials in active life expectancy among older Americans." Paper presented at the Meeting of the Gerontological Society of America. San Francisco, California. November 22, 2007. 
Cavelaars, A. E., A. E. Kunst, J. J. Geurts, L. Grotvedt, U. Helmert, E. Lahelma, O. Lundberg, J. Matheson, A. Mielck, A. Mizrahi, N. K. Rasmussen, E. Regidor, T. Spuhler, and J. P. Mackenbach. 1998. "Differences in self-reported morbidity by educational level: a comparison of 11 Western European countries." Journal of Epidemiology and Community Health 52(4): 219-227.

Chen, Z., X. O. Shu, G. Yang, H. Li, Q. Li, Y. T. Gao, and W. Zheng. 2006. "Nutrient intake among Chinese women living in Shanghai, China." British Journal of Nutrition 96(2): 393-399.

Clark, D. O., T. E. Stump, D. K. Miller, and J. S. Long. 2007. "Educational disparities in the prevalence and consequence of physical vulnerability." Journals of Gerontology Series B Psychological Sciences and Social Sciences 62(3): S193-7.

Cohen, S., G. Kaplan, and J. Salonen. 1999. "The role of psychological characteristics in the relation between socioeconomic status and perceived health." Journal of Applied Social Psychology 29(3): 445-468.

Crampin, A. C., J. R. Glynn, B. M. Ngwira, F. D. Mwaungulu, J. M. Ponnighaus, and D. K. Warndorff. 2003. "Trends and measurement of HIV prevalence in northern Malawi." AIDS 17(12): 1817-1825.

Crimmins, E. M., M. D. Hayward, and Y. Saito. 1996. "Differentials in active life expectancy in the older population of the United States." Journals of Gerontology B Psychological Science Social Science 51(3): 111-120.

Crimmins, E. M. and Y. Saito. 2001. "Trends in healthy life expectancy in the United States, 1970-1990: gender, racial, and educational differences." Social Science and Medicine 52(11): 1629-1641.

Cutler, D. and A. Lleras-Muney. 2006. "Education and health: evaluating theories and evidence." NBER Working Paper 12352.

Dalstra, J. A. A., A. E. Kunst, C. Borell, E. Breeze, E. Cambois, G. Costa, J. J. M. Geurts, E. Lahelma, H. Van Oyen, N. K. Rasmussen, E. Rigador, T. Spadea, and J. P. Mackenbach. 2005. "Socioeconomic differences in the prevalence of common chronic diseases: an overview of eight European countries." International Journal of Epidemiology 34(2): 316-326.

Damacena, G. N., M. T. Vasconcellos, and C. L. Szwarcwald. 2005. "Perception of health state and the use of vignettes to calibrate for socioeconomic status: results of the World Health Survey in Brazil, 2003." Cadernos de saúde pública/Ministérioda Saúde Fundacä̈ Oswald Cruz, Escola National de Saúde Pública 21 supp: 65-77.

Deboosere, P., S. Gadeyne, and H. Van Oyen. 2009. "The 1991-2004 evolution in life expectancy by education level in Belgium based on linked census and population register data." European Journal of Population 25(2):175-196.

Dennis, B. H., G. S. Zhukovsky, D. B. Shestov, C. E. Davis, A. D. Deev, H. Kim, and H. A. Tyroler. 1993. "The association of education with coronary heart disease mortality in the USSR Lipid Research Clinics Study." International Journal of Epidemiology 22(3): 420-427.

Desai, S. 1987. "The estimation of the health production function for low-income working men." Medical Care 25(7): 604-615.

Elo, I. T. and S. H. Preston 1996. "Educational differentials in mortality: United States, 1979-85." Social Science and Medicine 42(1): 47-57.

Elstad, J. I. 2005. "Childhood adversities and health variations among middle-aged men: a retrospective lifecourse study." European Journal of Public Health 15(1): 51-58. 
Ezendam, N. P., I. Stirbu, M. Leinsalu, O. Lundberg, R. Kalediene, B. Wojtyniak, P. Martikainen, J. P. Mackenbach, and A. Kunst. 2008. "Educational inequalities in cancer mortality differ greatly between countries around the Baltic Sea." European Journal of Cancer 44(3): 454-464.

Fawcett, J., T. Blakely, and A. Kunst. 2005. "Are mortality differences and trends by education any better or worse in New Zealand? A comparison study with Norway, Denmark and Finland, 1980-1990s." European Journal of Epidemiology 20(8): 683-691.

Feinstein, J. S. 1993. "The relationship between socioeconomic status and health: a review of the literature." Milbank Quarterly 71(2): 279-322.

Feldman, J. J., D. M. Makuc, J. C. Kleinman, and J. Cornoni-Hundley. 1989. "National trends in educational differentials in mortality." American Journal of Epidemiology 129(5): 919-933.

Fiscella, K. and P. Franks. 1997. "Does psychological distress contribute to racial and socioeconomic disparities in mortality?" Social Science and Medicine 45(12): 18051809.

Fortson, J. G. 2008. "The gradient in sub-Saharan Africa: socioeconomic status and HIV/AIDS.” Demography 45(2): 303-322.

Freedman, V. A., L. G. Martin, R. F. Schoeni, and J. C. Cornman. 2008. "Declines in latelife disability: The role of early- and mid-life factors." Social Science and Medicine 66(7): 1588-1602.

Fuchs, V. R. 1982. "Time preference and health: an exploratory study." In: V. R. Fuchs (ed.) Economic Aspects of Health. Chicago, University of Chicago: 93-120.

Fylkesnes, K., R. M. Musonda, K. Kasumba, Z. Ndhlovu, F. Mluanda, L. Kaetano, and C. C. Chipalia. 1997. "The HIV epidemic in Zambia: socio-demographic prevalence patterns and indications of trends among childbearing women." AIDS 11(3): 339-345.

Fylkesnes, K., R. M. Musonda, M. Sichone, Z. Ndhlovu, F. Tembo, and M. Monze. 2001. "Declining HIV prevalence and risk behaviours in Zambia: evidence from surveillance and population-based surveys." AIDS 15(7): 907-916.

Gale, C. R., G. D. Batty, and I. J. Deary. 2008. "Locus of control at age 10 years and health outcomes and behaviors at age 30 years: the 1970 British Cohort Study." Psychosomatic Medicine 70(4): 397-403.

Gallo, L. C. and K. A. Matthews. 2003. "Understanding the association between socioeconomic status and physical health: do negative emotions play a role?" Psychological Bulletin 129(1): 10-51.

Gilman, S. E., L. T. Martin, D. B. Abrams, L. Kubzansky, E. B. Loucks, R. Rende, R. Rudd, and S. L. Buka. 2008. "Educational attainment and cigarette smoking: a causal association?” International Journal of Epidemiology 37(3): 615-624.

Glynn, J. R., M. Caraël, A. Buvé, S. Anagonou, L. Zekeng, M. Kahindo, and R. Musonda. 2004. "Does increased general schooling protect against HIV infection? A study in four African cities." Tropical Medicine and International Health 9(1): 4-14.

Goldman, N. 2001. "Social inequalities in health: disentangling the underlying mechanisms." Annals of the New York Academy of Sciences 954: 118-139.

Graciani, A., J. R. Banegas, E. Lopez-Garcia, and F. Rodriguez-Artalejo. 2004. "Prevalence of disability and associated social and health-related factors among the elderly in Spain: a population-based study.” Maturitas 48(4): 381-392. 
Gregson, S., H. Waddell, and S. Chandiwana. 2001. "School education and HIV control in sub-Saharan Africa: from discord to harmony." Journal of International Development 13: 467-485.

Grosskurth, H., F. Mosha, J. Todd, K. Senkoro, J. Newell, A. Klokke, J. Changalucha, B. West, P. Mayaud, and A. Gavyole. 1995. "A community trial of the impact of improved sexually transmitted disease treatment on the HIV epidemic in rural Tanzania: 2. baseline survey results." AIDS 9(8): 927-934.

Grossman, M. 1975. "The correlation between health and schooling.” In: N. E. Terleckyj (ed.) Household Production and Consumption. New York, Columbia University Press for NBER: 147-211.

Guralnik, J. M., K. C. Land, D. Blazer, G. G. Fillenbaum, and L. G. Branch. 1993. "Educational status and active life expectancy among older blacks and whites." New England Journal of Medicine 329(2): 110-116.

Haan, M. N., G. A. Kaplan, and S. L. Syme. 1989. "Socioeconomic status and health: old observations and new thoughts." In: J. P. Bunker, D. S. Gomby, and B. H. Kehrer (eds.) Pathways to Health: The Role of Social Factors. Menlo Park, CA: Henry Kaiser Family Foundation, pp. 76-135.

Hargreaves, J. R. and J. R. Glynn. 2000. "Educational attainment and HIV-1 infection in developing countries: a systematic review." Tropical Medicine and International Health 7(6): 489-498.

Hayward, M. D. and B. K. Gorman. 2004. "The long arm of childhood: the influence of early-life social conditions on men's mortality." Demography 41(1): 87-107.

Hertzman, C., C. Power, S. Matthews, and O. Manor. 2001. "Using an interactive framework of society and lifecourse to explain self-rated health in early adulthood." Social Science and Medicine 53(12): 1575-1585.

Huisman, M., A. E. Kunst, M. Bopp, J. C. Borgan, C. Borrell, G. Costa, P. Deboosere, S. Gadeyne, M. Glickman, C. Marinacci, C. Minder, E. Regidor, T. Valkonen, and J. P. Mackenbach. 2005. "Educational inequalities in cause-specific mortality in middleaged and older men and women in eight Western European populations." Lancet 365(9458): 493-500.

Huong, D. L., H. Van Minh, U. Janlert, D. Van Do, and P. Byass. 2006. "Socio-economic status inequality and major causes of death in adults: a 5-year follow-up study in rural Vietnam." Public Health 120(6): 497-504.

Hurt, L. S., C. Ronsmans, and S. Saha. 2004. "Effects of education and other socioeconomic factors on middle age mortality in rural Bangladesh." Journal of Epidemiology and Community Health 58(4): 315-320.

Ito, S., R. Takachi, M. Inoue, N. Kurahashi, M. Iwasaki, S. Sasazuki, H. Iso, Y. Tsubono, and S. Tsugane. 2008. "Education in relation to incidence of and mortality from cancer and cardiovascular disease in Japan." European Journal of Public Health 18(5): 466-472.

Kalediene, R. and J. Petrauskiene. 2000. "Inequalities in life expectancy in Lithuania by level of education." Scandinavian Journal of Public Health 28(1): 4-9.

KC, S., B. Barakat, A. Goujon, V. Skirbekk, W. C. Sanderson, and W. Lutz. 2010. "Projection of populations by level of educational attainment, age, and sex for 120 countries for 2005-2050.” Demographic Research 22(15): 383-472.

Kelly, R., N. Kiwanuka, M. J. Wawer, D. Serwadda, N. K. Sewankambo, F. WabwireMangen, C. Li, J. K. Konde-Lule, T. Lutalo, F. Makumba, and R. H. Gray. 1999. “Age 
of male circumcision and risk of prevalent HIV infection in rural Uganda." AIDS 13(3): 399-405.

Kemna, H. J. 1987. "Working conditions and the relationship between schooling and health." Journal of Health Economics 6(3): 189-210.

Khang, Y., J. W. Lynch, S. Yang, S. Harper, S. Yun, K. Jung-Choi, and H. R. Kim. 2009. "The contribution of material, psychosocial, and behavioral factors in explaining educational and occupational mortality inequalities in a nationally representative sample of South Koreans: relative and absolute perspectives." Social Science and Medicine 68(5): 858-866.

Khang, Y. H., J. W. Lynch, and G. A. Kaplan. 2004. "Health inequalities in Korea: ageand sex-specific educational differences in the 10 leading causes of death." International Journal of Epidemiology 33(2): 299-308.

Kilander, L., L. Berglund, M. Boburg, B. Vessby, and H. Lithell. 2001. "Education, lifestyle factors and mortality from cardiovascular disease and cancer. A 25-year follow-up of Swedish 50-year-old men." International Journal of Epidemiology 30(5): 1119-1126.

Kilian, A. H., S. Gregson, B. Ndyanabangi, K. Walusaga, W. Kipp, G. Sahlmuller, G. P. Garnett, G. Asiimwe-Okiror, G. Kabagambe, and F. von Sonnenburg. 1999. "Reductions in risk behaviour provide the most consistent explanation for declining HIV-1 prevalence in Uganda." AIDS 13(3): 391-398.

Kinsey, T., A. Jemal, J. Liff, E. Ward, and M. Thun. 2008. "Secular trends in mortality from common cancers in the United States by educational attainment, 1993-2001." Journal of the National Cancer Institute 100(14): 1003-1012.

Kitagawa, E. M. and P. M. Hauser. 1973. Differential Mortality in the United States: A Study in Socioeconomic Epidemiology. Cambridge, Mass., Harvard University Press.

Kivimaki, M., D. A. Lawlor, G. Davy Smith, A. Kouvonen, M. Virtanen, M. Elovainio, and J. Vahtera. 2007. "Socioeconomic position, co-occurrence of behavior-related risk factors, and coronary heart disease: the Finnish Public Sector study." American Journal of Public Health 97(5): 874-879.

Kraus, J. F., N. O. Borhani, and C. E. Franti. 1980. "Socioeconomic status, ethnicity, and risk of coronary heart disease." American Journal of Epidemiology 111(4): 407-414.

Kunst, A. E. and J. P. Mackenbach. 1994. "The size of mortality differences associated with educational level in nine industrialized countries." American Journal of Public Health 84(6): 932-937.

Kurkure, A. P. and B. B. Yeole. 2006. "Social inequalities in cancer with special reference to South Asian countries." Asian Pacific Journal of Cancer Prevention 7(1): 36-40.

La Vecchia, C., E. Negri, and S. Frankeschi. 1992. "Education and cancer risk." Cancer 70(12): 2935-2941.

Laaksonen, M., K. Talala, T. Martelin, O. Rahkonen, E. Roos, S. Helakorpi, T. Laatikainen, and R. Prahala. 2008. "Health behaviours as explanations for educational level differences in cardiovascular and all-cause mortality: a follow-up of 60000 men and women over 23 years." European Journal of Public Health 18(1): 38-43.

Lairson, D., R. Lorimor, and C. Slater. 1984. "Estimates of the demand for health: males in the pre-retirement years." Social Science and Medicine 19(7): 741-747.

Lantz, P. M., J. W. Lynch, J. S. House, J. M. Lepkowski, R. P. Mero, M. A. Musick, and D. R. Williams. 2001. "Socioeconomic disparities in health change in a longitudinal study of US adults: the role of health-risk behaviors." Social Science and Medicine 53(1): 29-40. 
Leigh, J. P. 1983. "Direct and indirect effects of education on health." Social Science and Medicine 17(4): 227-234.

Leinsalu, M., D. Vågerö, and A. E. Kunst. 2003. "Estonia 1989-2000: enormous increase in mortality differences by education." International Journal of Epidemiology 32(6): 1081-1087.

Liang, J., J. F. McCarthy, A. Jain, N. Krause, J. M. Bennett, and S. Gu. 2000. "Socioeconomic gradient in old age mortality in Wuhan, China." Journal of Gerontology B Psychological Science Social Science 55(4): 222-233.

Lièvre, A., D. Alley, and E. Crimmins. 2008. "Educational differentials in life expectancy with cognitive impairment among the elderly in the United States." Journal of Aging and Health 20(4): 456-477.

Link, B. and J. Phelan. 2000. "The concept of fundamental causes in explaining social inequalities in health." Chapter 3 in: A. Maney and J. Ramos (ed.) Socioeconomic Conditions, Stress and Mental Disorders: Toward a New Synthesis of Research and Public Policy. Washington, D.C.: NIMH.

Link, B. G. and J. Phelan. 1995. "Social conditions as fundamental causes of disease." Journal of Health and Social Behavior, Special No.: 80-94.

Lowry, D. and Y. Xie. 2009. "Socioeconomic status and health differentials in China: convergence or divergence at older ages?" Research Report 24. Population Studies Center, University of Michigan.

Lutz, W. (ed.) 1994. Population-Development-Environment: Understanding their Interactions in Mauritius. Berlin, Springer Verlag.

Lutz, W. and A. Goujon. 2001. "The world's changing human capital stock: multi-state population projections by educational attainment." Population and Development Review 27(2): 323-339.

Lutz, W., A. Goujon, and G. Doblhammer-Reiter. 1999. "Demographic dimensions in forecasting: adding education to age and sex." In: W. Lutz, J. W. Vaupel, and D. A. Ahlburg (eds.). Frontiers of Population Forecasting. New Yok, The Population Council, pp. 42-58.

Lutz, W. and S. KC. 2010. "Dimensions of global population projections: what do we know about future population trends and structures?" Philosophical Transactions of the Royal Society B: Biological Sciences 365(1554): 2779-2791.

Mackenbach, J. P., V. Bos, O. Anderson, M. Cardano, G. Costa, S. Harding, A. Reid, O. Hemstrom, T. Valkonen, and A. E. Kunst. 2003. "Widening socioeconomic inequalities in mortality in six Western European countries." International Journal of Epidemiology 32(5): 830-837.

Mackenbach, J. P., A. E. Kunst, F. Groenhof, J. K. Borgan, G. Costa, F. Faggiano, P. Jozan, M. Leinsalu, P. Martikainen, J. Rychtarikova, and T. Valkonen. 1999. "Socioeconomic inequalities in mortality among women and among men: an international study." American Journal of Public Health 89(12): 1800-1806.

Majer, I., W. Nusselder, and A. Kunst. 2008. "Age profiles of mortality and disabilityrelated transitions in European countries. Estimates according to smoking status, and overweight status, educational level and marital status." Deliverable D18 for Micmac project, Department of Public Health, Erasmus MC, Rotterdam, the Netherlands. Michelo, C., I. F. Sandoy, and K. Fylkesnes. 2006. "Marked HIV prevalence declines in higher educated young people: evidence from population-based surveys (19952003) in Zambia.” AIDS 20(7): 1031-1038. 
Molla, M. T., J. H. Madans, and D. K. Wagener, 2004. "Differentials in adult mortality and activity limitation by years of education in the United States at the end of the 1990s." Population and Development Review 30(4): 625-646.

Mostafa, G. and J. K. van Ginneken. 2000. "Trends in and determinants of mortality in the elderly population of Matlab, Bangladesh." Social Science and Medicine 50(6): 763771.

Nagel, G., R. Peter, S. Braigs, S. Hermann, S. Rohrmann, and J. Linseisen. 2008. "The impact of education on risk factors and the occurrence of multimorbidity in the EPICHeidelberg cohort." BMC Public Health 8: 384.

Palloni, A. 2006. "Reproducing inequalities: luck, wallets, and the enduring effects of childhood health." Demography 43(4): 587-615.

Pappas, G., S. Queen, W. Hadden, and G. Fisher. 1993. "The increasing disparity in mortality between socioeconomic groups in the United States, 1960 and 1986." New England Journal of Medicine 329(2): 103-109.

Phelan, J. C. and B. G. Link. 2005. "Controlling disease and creating disparities: a fundamental cause perspective." Journal of Gerontology B Psychological Science Social Science 60, Spec. No 2: 27-33.

Pincus, T., L. F. Callahan, and R. V. Burkhauser. 1987. "Most chronic diseases are reported more frequently by individuals with fewer than 12 years of formal education in the age 18-64 United States population.” Journal of Chronic Disease 40(9): 865874.

Pitsavos, C. E., D. B. Panagiotakos, C. A. Chrysohoou, J. Skoumas, C. Stefanadis, and P. K. Toutouzas. 2002. "Education and acute coronary syndromes: results from the CARDIO2000 epidemiological study." Bulletin of the World Health Organization 80(5): 371-377.

Plavinski, S. L., S. I. Plavinskaya, and A. N. Klimov. 2003. "Social factors and increase in mortality in Russia in the 1990s: prospective cohort study." British Medical Journal 326(7401): 1240-1242.

Pollitt, R. A., K. M. Rose, and J. S. Kaufman. 2005. "Evaluating the evidence for models of life course socioeconomic factors and cardiovascular outcomes: a systematic review." BMC Public Health 5: 7.

Power, C. and J. Elliott. 2006. "Cohort profile: 1958 British birth cohort (National child development study).” International Journal of Epidemiology 35(1): 34-41.

Quigley, M., K. Munguti, H. Grosskurth, J. Todd, F. Mosha, K. Senkoro, J. Newell, P. Mayaud, G. ka-Gina, A. Klokke, D. Mabey, A. Gavyole, and R. Hayes. 1997. "Sexual behaviour patterns and other risk factors for HIV infection in rural Tanzania: a casecontrol study." AIDS 11(2): 237-248.

Qureshi, A. I., M. F. K. Suri, M. Saad, and L. N. Hopkins. 2003. "Educational attainment and risk of stroke and myocardial infarction." Medical Science Monitor 9(11): CR466-473.

Rau, R., G. Doblhammer, V. Canudas-Romo, and Z. Zhen. 2008. "Cause of death contributions to educational inequalities in mortality in Austria." European Journal of Population 24: 265-286.

Rice, N., S. Robone, and S. Smith. 2010. "International comparison of public sector performance: the use of Anchoring vignettes to adjust self-reported data." Evaluation 16(1): 81-101.

Rogers, A. 1975. Introduction to Multiregional Mathematical Demography. New York, John Wiley. 
Rogot, E., P. D. Sorlie, and N. J. Johnson. 1992. "Life expectancy by employment status, income, and education in the national longitudinal mortality study." Public Health Reports 107(4): 457-461.

Rosen, S. and P. Taubman. 1982. "Some socioeconomic determinants of mortality." In: J. v. d. Gaage, W. B. Neenam, and T. Tsukahana (eds.). Economics of Health Care. New York, Praeger Publishers, pp. 255-271.

Ruberman, W., E. Weinblatt, J. D. Goldberg, and B. S. Chaudharyl. 1984. "Psychosocial influences on mortality after myocardial infarction." New England Journal of Medicine 311(9): 552-559.

Rueda, S., L. Artazcoz, and V. Navarro. 2008. "Health inequalities among the elderly in Western Europe." Journal of Epidemiology and Community Health 62(6): 492-498.

Saavedra, J. M., S. Torres, B. Caro, Y. Escalante, E. De la Cruz, M. J. Duran, and F. A. Rodriguez. 2008. "Relationship between health-related fitness and educational and income levels in Spanish women." Public Health 122(8): 794-800.

Salmon, J.A., A. Tandon, and C. J. L. Murray. 2004. "Comparability of self rated health: cross sectional multi-country survey using anchoring vignettes." British Medical Journal 328(7434): 258-261.

Schrijvers, C. T., H. D. van de Mheen, K. Stronks, and J. P. Mackenbach. 1998. "Socioeconomic inequalities in health in the working population: the contribution of working conditions." International Journal of Epidemiology 27(6): 1011-1018.

Seeman, T., S. S. Merkin, E. Crimmins, B. Koretz, S. Charrette, and A. Karlamangla. 2008. "Education, income and ethnic differences in cumulative biological risk profiles in a national sample of US adults: NHANES III (1988-1994)." Social Science and Medicine 66(1): 72-87.

Shkolnikov, V. M., E. M. Andreev, D. Jasilionis, M. Leinsalu, O. I. Antonova, and M. McKee. 2006. "The changing relation between education and life expectancy in central and eastern Europe in the 1990s." Journal of Epidemiology and Community Health 60(10): 875-881.

Shkolnikov, V. M., D. A. Leon, S. Adamets, E. Andreev, and A. Deev. 1998. "Educational level and adult mortality in Russia: an analysis of routine data 1979 to 1994." Social Science and Medicine 47(3): 357-369.

Sihvonen, A. P., A. E. Kunst, E. Lahelma, T. Valkonen, and J. P. Mackenbach. 1998. "Socioeconomic inequalities in health expectancy in Finland and Norway in the late 1980s." Social Science and Medicine 47(3): 303-315.

Smith, G. D., D. Gunnel, and Y. Ben Shlomo. 2001. "Life-course approaches to socioeconomic differentials in cause specific adult mortality." In: D. Leon and G. Walt. Poverty, Inequality, and Health: An International Perspective. Oxford, Oxford University Press, pp. 88-124.

Smith, J., F. Nalagoda, M. J. Wawer, D. Serwadda, N. Sewankambo, J. Konde-Lule, T. Lutalo, L. Chuanjun, and R. H. Gray. 1999. "Education attainment as a predictor of HIV risk in rural Uganda: results from a population-based study." International Journal of STD and AIDS 10(7): 452-459.

Son, M., B. Armstrong, J-M. Choi, and T-Y. Yoon. 2002. "Relation of occupational class and education with mortality in Korea." Journal of Epidemiology and Community Health 56(10): 798-799.

Stronks, K., H. D. van de Mheen, C. W. N. Looman, and J. P. Mackenbach. 1996. "Behavioral and structural factors in the explanation of socioeconomic inequalities in health: an empirical analysis." Sociology of Health and Illness 18: 653-674. 
Valkonen, T. 1989. "Adult mortality and level of education: a comparison of six countries." In: J. Fox (ed.) Health Inequalities in European Countries. Aldershot: Gower Publishing Company, pp. 142-163.

Van Oort, F. V. A., F. J. Van Lenthe, and J. P. Mackenbach. 2005. "Material, psychosocial, and behavioural factors in the explanation of educational inequalities in mortality in the Netherlands." Journal of Epidemiology and Community Health 59(3): 214-220.

Vargas-Palacios, A., J. P. Gutiérrez, and V. Carreón-Rodriguez. 2006. "Health status identification and their relationship with socioeconomics and geographic characteristics: a population survey analysis in México." Salud Publica de Mexico 48(6): 482-489.

Viner, R. M. and T. J. Cole. 2005. "Adult socioeconomic, educational, social, and psychological outcomes of childhood obesity: a national birth cohort study." British Medical Journal 330(7504): 1354-1357.

Wadsworth, M. E. and D. J. Kuh. 1997. "Childhood influences on adult health: a review of recent work from the British 1946 national birth cohort study, the MRC National Survey of Health and Development." Paediatric and Perinatal Epidemiology 11(1): $2-20$.

WHO. 2000. The World Health Surveys (WHS). W. H. Organization. Geneva, WHO.

Wu, J., Y. Liu, K. Rao, Q. Sun, J. Qian, and Z. Li. 2004. "Education-related gender differences in health in rural China." American Journal of Public Health 94(10): 1713-1716.

Zhu, H. and Y. Xie. 2007. "Socioeconomic differentials in mortality among the oldest old in China." Research on Aging 29(9): 125-143. 